\title{
Correction to: Design Optimization of Hybrid FRP/RC Bridge
}

\author{
Vasileios S. Papapetrou ${ }^{1}$ - Ali Y. Tamijani ${ }^{1}$ • \\ Jeff Brown ${ }^{2}$ - Daewon Kim ${ }^{1}$
}

Published online: 31 May 2018

(C) Springer Science+Business Media B.V., part of Springer Nature 2018

\section{Correction to: Appl Compos Mater https://doi.org/10.1007/s10443-018-9691-3}

The original version of this article unfortunately contained an error.

There was an error regarding the captions of Figures 11 and 12, which are mistakenly interchanged. Although the cross-references for these figures are accurately described in the text, the correct figure captions should be:

Fig. 11 FE Model of the composite beam with the steel tubes

Fig. 12 Deformation pattern of the girder under static loading, units in $\mathrm{mm}$

The online version of the original article can be found at https://doi.org/10.1007/s10443-018-9691-3

Vasileios S. Papapetrou

papapetv@my.erau.edu
Ali Y. Tamijani
tamijana@erau.edu
Jeff Brown
jeff.brown1@erau.edu
Daewon Kim
daewon.kim@erau.edu

1 Aerospace Engineering Department, Embry-Riddle Aeronautical University, Daytona Beach, FL 32114, USA

2 Civil Engineering Department, Embry-Riddle Aeronautical University, Daytona Beach, FL 32114, USA 